\title{
Nomogram predicting long-term survival after the diagnosis of intrahepatic recurrence of hepatocellular carcinoma following an initial liver resection
}

\section{Reply to Drs. Ayubi and Safiri}

\author{
Akira Kobayashi $^{1} \cdot$ Tsuyoshi Notake $^{1}$
}

Received: 6 August 2017 / Accepted: 11 September 2017 / Published online: 7 October 2017

(C) Japan Society of Clinical Oncology 2017

We appreciate the interest of Drs. Ayubi and Safiri in our study and their insightful comments [1]. We will be able to investigate the validity of our constructed model once the number of events increases in the future. We believe that their comments will help to improve the quality of our future studies greatly.

As mentioned in their letter, multivariate results can be biased because of multicollinearity if this phenomenon is not checked during the univariate phase. The multicollinearity among the variables was investigated before their inclusion in the multivariate model, although we did not mention this point in our manuscript [2].

\section{References}

1. Ayubi E, Safiri S (2017) Nomogram predicting long-term survival after the diagnosis of intrahepatic recurrence of hepatocellular carcinoma following an initial liver resection: methodological issues. Int J Clin Oncol 22(4):803-804. doi:10.1007/s10147-017-1127-9

2. Notake T, Kobayashi A, Shinkawa H, Kawahara T, Shimizu A, Yokoyama T, Hasegawa K, Kokudo N, Matsuyama Y, Makuuchi M, S-i Miyagawa (2017) Nomogram predicting long-term survival after the diagnosis of intrahepatic recurrence of hepatocellular carcinoma following an initial liver resection. Int J Clin Oncol 22(4):715-725. doi:10.1007/s10147-017-1114-1

Akira Kobayashi

kbys@shinshu-u.ac.jp

1 First Department of Surgery, Shinshu University School of Medicine, 3-1-1 Asahi, Matsumoto 390-8621, Japan 